and supported on either side by a scrvant. A large basinful of cold water, fresh from the pump, was forcibly dashed upon the naked abdomen, and the process repeated again and again. The patient first panted from the shock, and subsequently became faint. Nothing more was required; after the third basinful, there was a profuse alvine evacuation, which literally poured away! The relief obtained was immediate. He was taken ont of the water, wiped with hot, dry napkins, and put into a warm bed. The bowels continued to act freely for some time, and the swelling of the abdomen decreased proportionately. The patient recovered completely, but not without our being apprehensive, for some days, of typhoid fever being a sequela of the attack.

Leamington, 1819 .

\section{CLINICAL OBSTETRICS.}

\section{A CASE OF}

UTERINE HAMORRHAGE OCCURRING AFTER THE EXPULSION OF THE PLACENTA,

AND IN WHICH THE INJECTION OF THE UTERUS WITH COLD WATER WAS RESORTED TO.

BY TYLER SMITH, M.D.

ONE OF THE PIYSICIANS TO QUERN ADELAIDE'S LYING-IN YOSPITAL. HONORARY MEMBER OF THE DUBLIN OHSTETRICAL SOCLETY.

Emma B-, a poor needle-woman, between seventeen and eighteen years of age, an out-patient of Queen Adelaide's Hospital, was delivered, at half-past two A.M., Dec. 5th, after a tedious labour. During her pregnancy, she had sat generally fifteen hours a day at waistcoat-making, with her head bent towards her knees. This position caused anteversion of the womb, to an extent which is sometimes noticed in multiparous women, when the abdominal walls has been lax and weak but which $I$ have never before seen in a primipara. The head presented, in the fourth position; the cervix uteri was low in the pelvis, and the anterior lip of the os nteri very prominent. The pelvis was small, in fact, the poor girl was scarcely full gxown. These circumstances were quite sufficient to account for a labour of upwards of twenty.four hours.

The placenta came away naturally, both placenta and cord being large. Very soon afterwards hæmorrhage began to take place; the blood oozing from the uterus, not continuously, but at intervals, and to a very considerable extent. The hæmorrhage continued, in spite of external pressure upon the uterus; grasping of the organ from without: the intrcduction of the hand, previously dipped in cold water; irritating the internal surface of the uterns with the tips of the fingers; plugging the uterine cavity with a tampon dipped in vinegar-and-water drinking cold water; cold douching of the abdomen and vulva sucking of the mamma by the mother of the patient; and every other means which could be put in practice in a miserable garret, in the middle of a December night. The uterus would contract upon the use of any stimulus for a few moments, bu it could not be made to contract permanently; it would slowly relax after contraction, and allow some blood to slip away, in spite of the most energetic mechanical pressure. Matters proceeded thus, until the poor creature became insensible from loss of blood. An enema syringe was procured, and as much as two hand-basinfuls of cold water, altogether, was injected into the uterus, the hand remaining in the cavity, to note its effects. The injection was thrown in at intervals. As soon as the organ began to relax, it was irrigated with cold water until it contracted again. In injecting the uterus $I$ had the valuable assistance of Mr. Stillman.

In this way the hæmorrhage was arrested; and the hand being withdrawn, the finger was introduced, from time to time, to the os uteri; and its being returned without a stain of blood showed that the uterus had permanently contracted. The patient slowly recovered her sensibility. She was kept in the supine position for twenty-four hours, and supported by stimulants and proper nutriment, supplied by some benevolent ladies who were made acqnainted with her necessitous condition. She gradually acquired strength, and was able to suckle her child. There was lit tle tenderness of the abdomen. At first there was no lochial discharge; but on the second day this secretion appeared naturally. The effects of the hæmorrhage were seen for some days in violent beadach; and in gasping respiration, (showing the effects of loss of blood on the medulla oblongata, whenever her position was changed.

In cases of flooding, it must be kept in mind that the loss of blood is but a symptom of the uterine inertia which exists; and that it is the uterine inertia which we really have to treat. While the hand was in the uterus, I observer some interesting facts relating to its mode of contraction; and probably, from the length of time during which the flooding continued, no one ever had a bettcr opportunity of observing the action of the uterus. When the abdomen or any other excitor surface was douched, or when the breast was irritated, the organ did not immediately contract, but began slowly to close upon the hand, after the cxpiration of abont a minute. I noticed this also when the cold water was injected, which renders it extremely probable that the contraction of the uterus, upon being injected, was a reflex action. This slowness of the uterine reflex actions is remarkable, and contrasts greatly with the instant contraction of the respiratory muscles on sprinkling the chest or face with cold water. The slow contraction depends upon the admixture of the ganglionic and spinal systems in the uterine nerves.

I observed another point worth noting: as the respiration was laboured, I had the face sprinkled with cold water, and to my surprise the uterus answered this stimulus quite as readily as it did the pouring of water in bulk upon the abdomen. This was repeated several times. Nothing could prove more beautifully the reflex power of the uterus. This is not the first time, in which irritation of the trifacial nerve has been observed to excite the uterus. Mr. Barlow has pointed out, that in a case related by Harver, uterine contraction was induced before delivery by stimulating the nostril. In both cases it must have been the fifth pair of nerves which excited the uterus to reflex action.

While the hand was in the uterus, and I was examining the strength of the patient by feeling the pulsation in the abdominal aorta, it struck me how futile must be the plan which some accoucheurs have advised, of pressing upon the aorta and cava through the posterior walls of the uterus-futile because of the situations at which the uterine arteries and the uterine veins reach the aorta and vena cava. I had reason, too, to be glad that bleeding was not practised in this case, as is sometimes recommended in laborious labours. The lancet should never be used in labour without the recollection of the possilility of uterine hæmorrhage, and that the blood taken by a vein may be absolutely necessary to save life.

After the cessation of the hromorrlage, bottles of hot water were applied to the epigastrium and the feet, to preserve the animal heat, but it was found difficult to give the patient any internal stimulant. The masseter muscles were strongly contracted, and the teeth clenched; when brandy was placed in the mouth, it was returned. In this emergency, I put into operation the plan suggested and practised by Mr. Simpson, of Stamford-namely, that of filling the mouth with brandy, and then sprinkling cold water upon the face and neck. Deglutition was instantly produced in this manner, and brandy several times introduced into the stomach, when such a stimulantwas of infinite aid to the preservation of the patient's life. I am sure the profession will find the plan of great value in many of the emergencies of practice. The case itself proves the great power of the injection of cold water in reducing hæmorrbage, and inducing safe uterine contraction. I am convinced, that both in this case and in the case $I$ detailed in The Lancet, (July 7,1819 ,) tho patients would have been lost without it.

Bolton-street, Piccadilly, Dec. 1849.

\section{ON CERTAIN IMPORTANT POINTS IN THE} CHEMISTRY \& PATHOLOGY OF THE URINE. By AR'THUR HILL HASSALL, M.B. Lond. (Continued from p. 666.)

On Sugar.-I have now to make known the remarkable fact of the almost constant presence of sugar in the urine, and this in persons of opposite and dissimilar habits of body, and where no suspicion exists of a diabetic tendency.

The reason that this fact has remained so long undiscovered wonld appear to be dependent upon the circumstance, that the tests ordinarily employed for the detection of sugar fail to reveal the presence of this substance, when not existing in the urine in large quantities.

Thus the specific gravity test will not detect sugar unless it exist in tolerably large quantity.

The liquor potassae test, although more sure and delicate, requires a good deal of sugar before it will act. 